\title{
Low-Temperature Passivation of Amorphous-Silicon Thin-Film Transistors With Supercritical Fluids
}

\author{
Chih-Tsung Tsai, Po-Tsun Liu, Member, IEEE, Ting-Chang Chang, Chen-Wen Wang, \\ Po-Yu Yang, and Fon-Shan Yeh
}

\begin{abstract}
In this letter, supercritical $\mathrm{CO}_{2}\left(\mathrm{SCCO}_{2}\right)$ fluids technology is employed for the first time to effectively passivate the defect states in hydrogenated amorphous-silicon thin-film transistors (a-Si:H TFTs) at low temperature $\left(150{ }^{\circ} \mathrm{C}\right)$. With the high transport and diffusion properties of $\mathrm{SCCO}_{2}$ fluids, it is proposed to act as a transporter in delivering the $\mathrm{H}_{2} \mathrm{O}$ molecules into the amorphous-silicon film and repairing defect states by the $\mathrm{H}_{2} \mathrm{O}$ molecules. In addition, the propyl alcohol is used as the surfactant between nonpolar-SCCO $\mathrm{O}_{2}$ fluids and polar- $\mathrm{H}_{2} \mathrm{O}$ molecules for mingling $\mathrm{H}_{2} \mathrm{O}$ molecules uniformly with the $\mathrm{SCCO}_{2}$ fluids. After the treatment of $\mathrm{SCCO}_{2}$ fluids mixed with water and propyl alcohol, the a-Si:H TFT exhibited superior transfer characteristics and lower threshold voltage. The improvement in electrical characteristics could be verified by the significant reduction of density of states in the mobility gap of amorphous-silicon.
\end{abstract}

Index Terms-Amorphous-silicon thin-film transistors (a-Si:H TFTs), density of states (DOSs), supercritical $\mathrm{CO}_{2}\left(\mathrm{SCCO}_{2}\right)$ fluids technology.

\section{INTRODUCTION}

A MORPHOUS-silicon thin-film transistors (a-Si:H TFTs) are widely used in the active matrix liquid crystal displays as switch devices [1], [2]. The excellent transfer characteristics are thereby demanded, such as high mobility and lower threshold voltage. In particular, in recent years, the fabrication of a-Si:H TFTs tends to be implemented at lowtemperature processes for cost down and convenience to plastic substrates [3]. The performance of low-temperature-fabricated a-Si:H TFTs, however, is unsuitable for applying to the display technology, due to the poor a-Si film dielectrics with plenty of defects. For improving the electrical characteristics of a-Si TFTs, it is necessary to passivate the defects in mobility gap of a-Si:H film. The $\mathrm{O}_{2} / \mathrm{H}_{2} / \mathrm{NH}_{3}$ plasma treatments were traditionally applied to reduce these defects [4], [5].

Manuscript received March 13, 2007; revised April 12, 2007. This work was supported in part by MOE ATU Program 95W803, the National Science Council, Taiwan, R.O.C., under Contract NSC-95-2120-M-110-003 and Contract NSC 95-2221-E-009-254-MY2 and in part by MOEA Technology Development for Academia Project 94-EC-17-A-07-S1-046. The review of this letter was arranged by Editor J. Sin.

C.-T. Tsai and F.-S. Yeh are with the Institute of Electronics Engineering, National Tsing Hua University, Hsinchu 300, Taiwan, R.O.C.

P.-T. Liu, C.-W. Wang, and P.-Y. Yang are with the Department of Photonics and Display Institute, National Chiao Tung University, Hsinchu 300, Taiwan, R.O.C.

T.-C. Chang is with the Department of Physics and Institute of ElectroOptical Engineering, Center for Nanoscience and Nanotechnology, National Sun Yat-set University, Kaohsiung 804, Taiwan, R.O.C. (e-mail: tcchang@ mail.phys.nsysu.edu.tw).

Digital Object Identifier 10.1109/LED.2007.897869
Moreover, in other records, the high-pressure $\mathrm{H}_{2} \mathrm{O}$ vapor was used to reduce the dangling bonds at the $\mathrm{SiO}_{2} / \mathrm{Si}$ interface and grain boundaries of poly-Si TFTs, with forming $\mathrm{Si}-\mathrm{O}, \mathrm{Si}-\mathrm{H}$, and $\mathrm{Si}-\mathrm{OH}$ bonds [6]-[9]. Nevertheless, these methods always require a high-temperature ambient $\left(>200{ }^{\circ} \mathrm{C}\right)$ and long processing duration. For example, high-pressure $\mathrm{H}_{2} \mathrm{O}$ vapor method needs high temperature $\left(>250{ }^{\circ} \mathrm{C}\right)$ to achieve enough pressure for the $\mathrm{H}_{2} \mathrm{O}$ molecules diffusing into poly-silicon film to repair silicon dangling bonds. In this letter, supercritical $\mathrm{CO}_{2}$ $\left(\mathrm{SCCO}_{2}\right)$ fluids technology, which is a low-temperature defectpassivation processing $\left(150{ }^{\circ} \mathrm{C}\right)$, is proposed to effectively decrease the density of states (DOSs) in a-Si:H TFTs. The $\mathrm{SCCO}_{2}$ fluids have been applied to remove photoresist and impurity in the integrated-circuit (IC) fabrications [10]. Besides, it is an operative method to extract moisture from nanoscale structures, such as porous dielectric material and carbon nanotube [11], [12]. The $\mathrm{SCCO}_{2}$ fluids holds liquidlike property that allows it to carry the $\mathrm{H}_{2} \mathrm{O}$ molecules [12], [13]. Additionally, it also keeps gaslike and high-pressure properties to efficiently diffuse into the amorphous thin film. Therefore, $\mathrm{SCCO}_{2}$ fluids could be used to transport the $\mathrm{H}_{2} \mathrm{O}$ molecules into the amorphoussilicon film and repairing defects by the $\mathrm{H}_{2} \mathrm{O}$ molecules at low temperature.

\section{EXPERIMENTAL PROCEDURES}

Conventional back-channel etching a-Si:H TFTs on glass substrate were investigated with $\mathrm{SCCO}_{2}$ fluids in this letter. The trilayer a-SiN ${ }_{x} / \mathrm{a}-\mathrm{Si}: \mathrm{H} / \mathrm{n}^{+}-\mathrm{a}-\mathrm{Si}: \mathrm{H}$ with thickness of $300 \mathrm{~nm} / 150 \mathrm{~nm} / 50 \mathrm{~nm}$, respectively, were formed over the patterned chromium gates in a plasma-enhancement chemicalvapor-deposition (PECVD) system at $300{ }^{\circ} \mathrm{C}$. Afterward, the source/drain metal film was deposited and patterned by microlithography and etch processes. For improving the electric characteristics, one group of a-Si:H TFTs was placed in the supercritical-fluid system at $150{ }^{\circ} \mathrm{C}$ for $120 \mathrm{~min}$, where it was injected with a $3000 \mathrm{psi}$ of $\mathrm{SCCO}_{2}$ fluids mixed with $5 \mathrm{vol} . \%$ of propyl alcohol and $5 \mathrm{vol} . \%$ of pure $\mathrm{H}_{2} \mathrm{O}$. The propyl alcohol plays a role of surfactant between nonpolar- $\mathrm{SCCO}_{2}$ fluids and polar- $\mathrm{H}_{2} \mathrm{O}$ molecules, so that the $\mathrm{H}_{2} \mathrm{O}$ molecules would distribute uniformly over the $\mathrm{SCCO}_{2}$ fluids. In addition, another group of a-Si:H TFTs with no $\mathrm{SCCO}_{2}$ treatment was taken as the control sample and only baked on a hot plate at $150{ }^{\circ} \mathrm{C}$ for $120 \mathrm{~min}$.

The transfer and output characteristics of a-Si:H TFTs were measured by HP $4156-\mathrm{A}$ semiconductor analyzer at $30^{\circ} \mathrm{C}$. For 


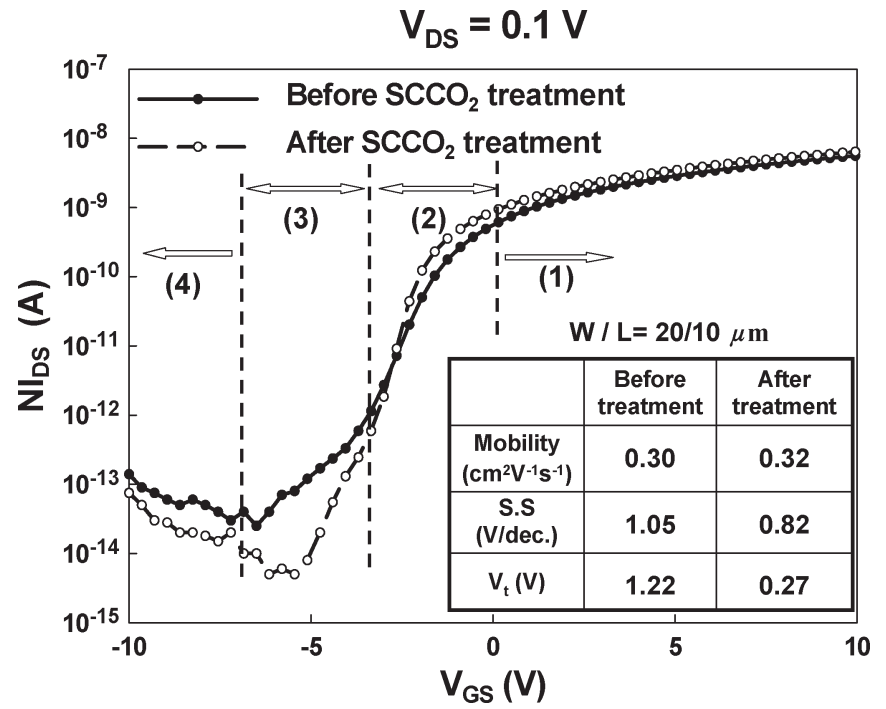

Fig. 1. Transfer characteristic of identical a-Si:H TFT before and after the $\mathrm{SCCO}_{2}$ treatment. The gate-bias regions (1), (2), (3), and (4) are expressed sequentially as above-threshold, forward subthreshold, reverse subthreshold, and Pool-Frenkel emission regions [14], respectively.

extracting activation energy, the transfer characteristics of TFT devices were also measured at different temperatures, and the DOSs of TFTs were obtained from the resultant analysis of activation energy.

\section{RESUlTS AND DISCUSSION}

Fig. 1 shows the transfer characteristic of identical a-Si:H TFT, before and after $\mathrm{SCCO}_{2}$ treatment. The a-Si:H TFT, with a ratio of channel length $(L)$ to width $(W) 10 \mu \mathrm{m} / 20 \mu \mathrm{m}$, was operated in linear region at $V_{\mathrm{DS}}=0.1 \mathrm{~V}$. The threshold voltage $\left(V_{t}\right)$ of a-Si:H TFTs was defined as normalized drain current $\left(\mathrm{NI}_{\mathrm{DS}}=L \times I_{\mathrm{DS}} / W\right)$ reaching $10^{-9}$ A. The subthreshold swing (SS) was calculated from $\mathrm{NI}_{\mathrm{DS}}=10^{-12} \mathrm{~A}$ to $10^{-10} \mathrm{~A}$, which is a forward subthreshold region. In Fig. 1, after $\mathrm{SCCO}_{2}$ treatment, it is observed that the a-Si:H TFT device exhibits a lower threshold voltage, lower SS (from $1.05 \mathrm{~V} / \mathrm{dec}$. to $0.82 \mathrm{~V} / \mathrm{dec}$.), and slightly enhancing mobility (from $0.30 \mathrm{~cm}^{2}$. $\mathrm{V}^{-1} \cdot \mathrm{s}^{-1}$ to $0.32 \mathrm{~cm}^{2} \cdot \mathrm{V}^{-1} \cdot \mathrm{s}^{-1}$ ). For a-Si:H TFTs, the SS and mobility are dependent on the deep states and tail states in the mobility gap of a-Si:H film, respectively [14], [15]. This indicates that the $\mathrm{SCCO}_{2}$ fluids could successfully deliver the $\mathrm{H}_{2} \mathrm{O}$ molecules into a-Si:H film at $150{ }^{\circ} \mathrm{C}$ and terminating defects by the $\mathrm{H}_{2} \mathrm{O}$ molecules, particularly for deep states. The lower threshold voltage could be attributed to the relaxing of trapped charge from $\operatorname{SiN}_{x}$ and the decrease of deep states in a-Si:H film [15]. Additionally, the improvement of leakage current in the reverse subthreshold regime, as shown in region (3) of Fig. 1, can support the proposed contention again, due to the repairing of DOSs at the back-channel interface [16].

The output characteristic of a-Si:H TFT was shown in Fig. 2, and the higher saturation current is achieved after the $\mathrm{SCCO}_{2}$ treatment. The improvement of saturation current is mainly caused by the lowering of threshold voltage, as a result of insignificant variation in mobility. Besides, after the $\mathrm{SCCO}_{2}$ treatment, a fine contact between a-Si:H and source/drain

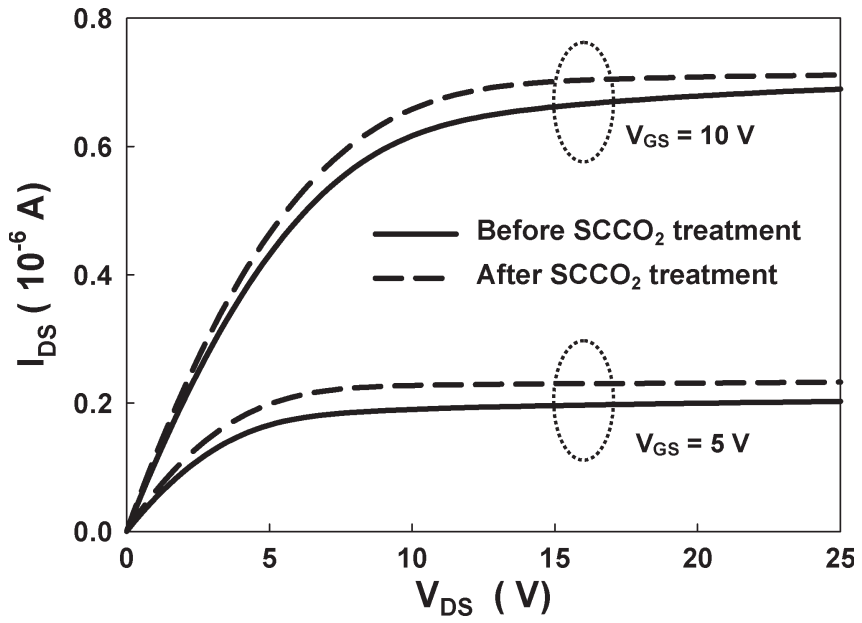

Fig. 2. Output characteristic of a-Si:H TFT before and after the $\mathrm{SCCO}_{2}$ treatment.

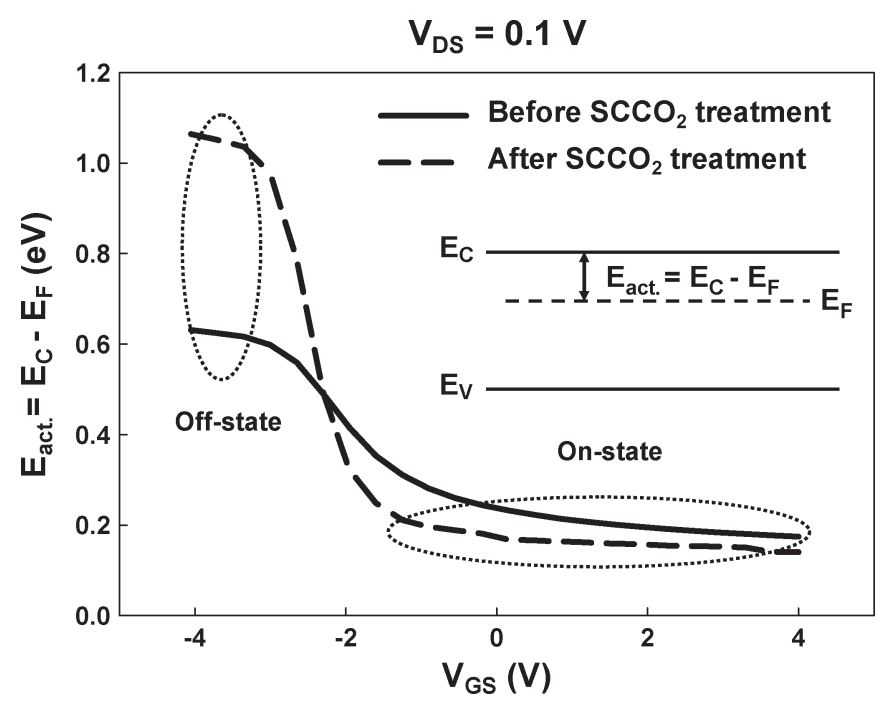

Fig. 3. Plot of activation energy versus gate bias before and after the $\mathrm{SCCO}_{2}$ treatment. The inset shows the definition of activation energy $\left(E_{\text {act. }}\right)$.

metal is retained because of no current crowding in the output characteristics.

For further study, the activation energy, thereby, was extracted from the transfer characteristics at different measured temperatures [17], and $V_{\mathrm{DS}}=0.1 \mathrm{~V}$. The activation energy is defined as $E_{\text {act. }}=E_{\mathrm{C}}-E_{\mathrm{F}}$, where $E_{\mathrm{C}}$ and $E_{\mathrm{F}}$ is the conduction band and the Fermi-level energy of a-Si:H film, respectively, as shown in the inset of Fig. 3. The Fig. 3 shows the plot of activation energy versus the gate-bias voltages. In transient region, i.e., from OFF-state to ON-state, the sharper variation of activation energy exhibits the higher capability for gate-to-control transistor, lower DOSs, and better SS [15], [17]. After the $\mathrm{SCCO}_{2}$ treatment, the variation rate of activation energy in transient region increases obviously, so that the improvement of SS is expected exactly, as shown in Fig. 1. Besides, the lower and higher activation energy at ON-state and OFF-state are corresponding to the higher mobility in the above-threshold region and lower leakage in reverse subthreshold region, respectively. 


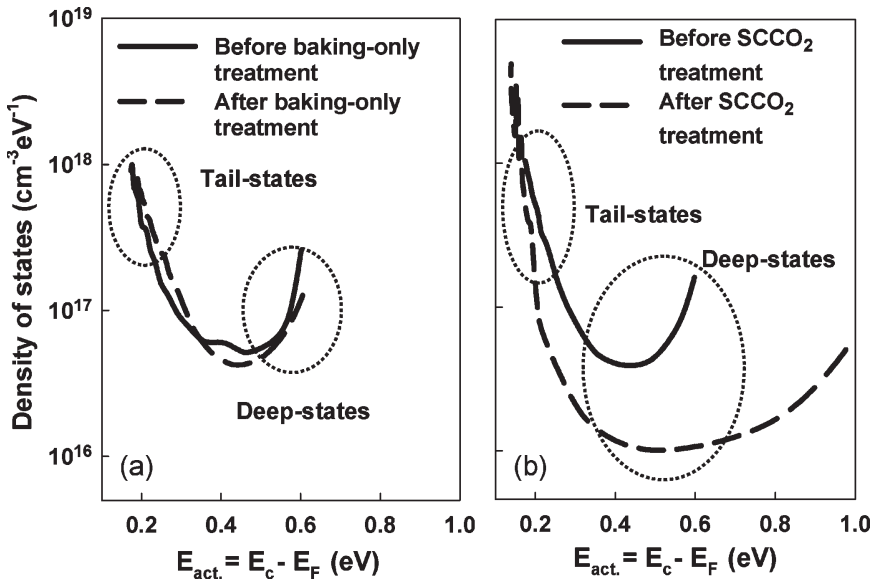

Fig. 4. DOSs in mobility gap of a-Si:H film. (a) a-Si:H TFT with no $\mathrm{SCCO}_{2}$ treatment before and after the hot baking on a hot plate at $150{ }^{\circ} \mathrm{C}$ for $120 \mathrm{~min}$, which was taken as the control sample. (b) a-Si:H TFT device before and after the $\mathrm{SCCO}_{2}$ treatment.

The DOSs in mobility gap of a-Si:H film are shown in Fig. 4. This distribution is calculated by the followed equation [17], which is operative in the SS region, i.e., the transient region of Fig. 3

$$
g\left(E_{\text {act. }}\right) \simeq-\frac{\varepsilon_{i}}{q \times d_{i} \times t} \times \frac{1}{\frac{d E_{\text {act. }}}{d V_{\mathrm{GS}}}}
$$

where $G\left(E_{\text {act. }}\right), \varepsilon_{i}, d_{i}$, and $t$ sequentially are the DOS at $E_{\text {act. }}$, gate dielectric permittivity, gate dielectric thickness, and a-Si:H layer thickness, respectively. From Fig. 4(a), it indicates that the electrical characteristics of a-Si:H TFTs would not be improved under the heating at $150{ }^{\circ} \mathrm{C}$ alone, because of no obvious modification in the DOSs being observed after a baking treatment. In Fig. 4(b), after the $\mathrm{SCCO}_{2}$ treatment, the deep states that are caused mainly by the existence of dangling bonds are evidently reduced from $10^{17} \mathrm{~cm}^{-3} \cdot \mathrm{eV}^{-1}$ to $10^{16} \mathrm{~cm}^{-3} \cdot \mathrm{eV}^{-1}$, and partial tail states also decrease. Consequently, it is believed that the $\mathrm{H}_{2} \mathrm{O}$ molecules could be effectively transferred into a-Si:H film by $\mathrm{SCCO}_{2}$ fluids at $150{ }^{\circ} \mathrm{C}$ and effectively passivating the dangling bonds by the $\mathrm{H}_{2} \mathrm{O}$ molecules [6]-[9]. Because primary variation occurs in deep states, the enhancement, thereby, is conspicuous in SS but not in the mobility for the $\mathrm{SCCO}_{2}$-treated a-Si:H TFT.

\section{CONCLUSION}

In this letter, the $\mathrm{SCCO}_{2}$ fluids technology is successfully used to carry the $\mathrm{H}_{2} \mathrm{O}$ molecules into the a-Si:H film at $150{ }^{\circ} \mathrm{C}$ and deactivating the defects. From the experimental results, the deep states are obviously reduced from $10^{17} \mathrm{~cm}^{-3} \cdot \mathrm{eV}^{-1}$ to $10^{16} \mathrm{~cm}^{-3} \cdot \mathrm{eV}^{-1}$, and some tail states are depressed via this proposed $\mathrm{SCCO}_{2}$ processing. Hence, better SS and lower threshold voltage are gained after the $\mathrm{SCCO}_{2}$ fluids treatment. Additionally, a superior output characteristic is kept during the $\mathrm{SCCO}_{2}$ processing. This proposed technology, therefore, is applicable to effectively improve the electrical characteristics of a-Si:H TFTs and consistent with the low-temperature manufacture processes.

\section{REFERENCES}

[1] T. Tanaka, H. Asuma, K. Ogawa, Y. Shinagawa, K. Ono, and N. Konishi, "An LCD addressed by a-Si:H TFTs with peripheral poly-Si TFT circuits," in IEDM Tech. Dig., 1993, pp. 389-392.

[2] Y. He, R. Hattori, and J. Kanicki, "Current-source a-Si:H thin-film transistor circuit for active-matrix organic light-emitting displays," IEEE Electron Device Lett., vol. 21, no. 12, pp. 590-592, Dec. 2000.

[3] C. S. Yang, L. L. Smith, C. B. Arthur, and G. N. Parsons, "Stability of low-temperature amorphous-silicon thin film transistors formed on glass and transparent plastic substrates," J. Vac. Sci. Technol. B, Microelectron. Process. Phenom., vol. 18, no. 2, pp. 683-689, Mar. 2000.

[4] H. C. Cheng, F. S. Wang, and C. Y. Huang, "Effects of $\mathrm{NH}_{3}$ plasma passivation on N-channel polycrystalline silicon thin-film transistors," IEEE Trans. Electron Devices, vol. 44, no. 1, pp. 64-68, Jan. 1997.

[5] H. N. Chern, C. L. Lee, and T. F. Lei, "The effects of $\mathrm{H}_{2}-\mathrm{O}_{2}$-plasma treatment on the characteristics of polysilicon thin-film transistors," IEEE Trans. Electron Devices, vol. 40, no. 12, pp. 2301-2306, Dec. 1993.

[6] T. Sameshima, M. Satoh, K. Sakamoto, A. Hisamatsu, K. Ozaki, and K. Saitoh, "Heat treatment of amorphous and polycrystalline silicon thin films with $\mathrm{H}_{2} \mathrm{O}$ vapor," Jpn. J. Appl. Phys., vol. 37, pt. 2, no. 2A, pp. L112-L114, Feb. 1998.

[7] M. Kunii, "Evaluation of electrical characteristics and trap-state density in bottom-gate polycrystalline thin film transistors processed with highpressure water vapor annealing," Jpn. J. Appl. Phys., vol. 45, no. 2A, pp. 660-665, Feb. 2006.

[8] K. Kitahara, K. Ohnishi, Y. Katoh, R. Yamazaki, and T. Kurosawa, "Analysis of defects in polycrystalline silicon thin films using Raman scattering spectroscopy," Jpn. J. Appl. Phys., vol. 42, pt. 1, no. 11, pp. 67426747, Nov. 2003.

[9] T. Sameshima, K. Sakamoto, Y. Tsunoda, and T. Saitoh, "Improvement of $\mathrm{SiO}_{2}$ properties and silicon surface passivation by heat treatment with high-pressure $\mathrm{H}_{2} \mathrm{O}$ vapor," Jpn. J. Appl. Phys., vol. 37, pt. 2, no. 12A, pp. L1452-L1454, Dec. 1998.

[10] G. L. Weibel and C. K. Ober, "An overview of supercritical $\mathrm{CO}_{2}$ applications in microelectronics processing," Microelectron. Eng., vol. 65, no. 1/2, pp. 145-152, Jan. 2003.

[11] S. Ogawa, T. Nasuno, M. Egami, and A. Nakashima, "Formation of mechanically strong low- $\kappa$ film using supercritical fluid dry technology," in Proc. IEEE Int. Interconnect Technol. Conf., 2002, pp. 220-222.

[12] P. T. Liu, C. T. Tsai, T. C. Chang, K. T. Kin, P. L. Chang, C. M. Chen, and H. F. Cheng, "Activation of carbon nanotube emitters by using supercritical carbon dioxide fluids with propyl alcohol," Electrochem. Solid-State Lett., vol. 9, no. 4, pp. G124-G126, Feb. 2006.

[13] T. Fukuda and H. Yanazawa, "A novel method of removing impurities from multilevel interconnect materials," Jpn. J. Appl. Phys., vol. 43, no. 3 , pp. 936-939, Mar. 2004.

[14] P. Servati and A. Nathan, "Modeling of the static and dynamic behavior of hydrogenated amorphous-silicon thin-film transistors," J. Vac. Sci. Technol. A, Vac. Surf. Films, vol. 20, no. 3, pp. 1038-1042, May/Jun. 2002.

[15] M. Powell, "The physics of amorphous-silicon thin-film transistors," IEEE Trans. Electron Devices, vol. 36, no. 12, pp. 2753-2763, Dec. 1989.

[16] P. Servati and A. Nathan, "Modeling of the reverse characteristics of a-Si:H TFTs," IEEE Trans. Electron Devices, vol. 49, no. 5, pp. 812-819, May 2002.

[17] T. Globus, H. C. Slade, M. S. Shur, and M. Hack, "Density of deep bandgap states in amorphous-silicon from the temperature dependence of thin film transistor current," in Proc. Mater. Res. Soc., 1994, vol. 336 , p. 823 . 